\title{
XXXIX.
}

\section{Vorläufige Mittheilung.}

\author{
Von
}

Dr. v. Rabenau.

Im Laufe des verflossenen Jahres habe ich eine Reihe von Urinen paralytischer Geisteskranker untersucht und bin dabei zu Resultaten gelangt, welche von Interesse sein dürften. Ich habe im Ganzen den Urin voll 36 Paralytikern untersucht und bei 20 von diesen zu irgend einer Zeit liwweiss im Harn gefunden. Ich glaube mich schon jetzt zu dem Schlusse berechtigt, dass die Albuminurie wenigstens in einem Theile dieser Fälle in irgend einer Weise abhängig war von der Gehirnerkrankung und zwar direct von dieser nicht etwa von einer durch dieselbe bedingten secundären Affection anderer Organe. Ausser etwaigen Nierenerkrankungen waren in den von mir beobachteten Fällen kaum jemals Erkrankungen nachweisbar, welche erfahrungsgemäss Albuminurie bedingen können. Die Nierenerkrankungen glaube ich, wenigstens in der Mehrzahl der Fälle, als Ursache des Eiweissgehaltes des Urins ausschliessen zu dürfen, obwohl dieselben post mortem häufig genug gefunden werden - von obigen 20 Kranken habe ich bis jetzt 10 secirt und 5 mal deutliche Nierenerkrankung gefunden - ; erstens habe ich nie in eiweisshaltigen Urinen Paralytischer Harncylinder gefunden, und zweitens waren im Leben nie anderweitige Symptome einer Nierenerkrankung vorhanden.

Auf der anderen Seite sprachen für einen cerebralen Ursprung der Albuminurie gewisse Begleiterscheinungen. Ich habe wiederholt gefunden, dass während eines leichten paralytischen Anfalls, der von keinem oder nur geringem Fieber begleitet war, der Urin Eiweiss enthielt, während er vorher und nachher frei davon war. Ferner habe ich bei verschiedenen Kranken, welche schnell körperlich und geistig verfielen, Fiweiss gefunden, welches verschwand, sobald die Kranken sich erholten. Die Albuminurie konnte hier nicht als Ursache des Verfalls angesehen werden, da die ausgeschiedenen Eiweissmengen hierzu zu gering waren. Ich glaube eben, dass beide Symptome abhängig waren von ein und demselben centralen Process. Hiermit wahrscheinlich zusammenfallend sind die Fälle, wo in den letzten Tagen oder Wochen ante mortem Albuminurie bestand. Weitere Schlüsse werden sich erst aus längere Zeit fortgesetzten Untersuchungen ziehen lassen. 
Bemerken will ich noch, dass ich, um vor Täuschungen sicher zu sein, stets mittelst mehrerer Methoden (c. Neubauer und Vogel) den fraglichen Urin prüfte. Am Sichersten und bei der nöthigen Uebung am Bequemsten ist die von Heller: "Man giesst in ein Reagenzglas $1 / 2^{\prime}$ hoch reine Salpeterräure und überschättet dieselbe mittelst einer Pipette vorsichtig mit dem klar filtrirten Harn. Bei Gegenwart von Eiweiss bildet sich an der Berührungsfläche beider Flüssigkeiten ein nach oben und unten scharf begrenzter Ring, der bei einiger Uebung sichere Schlüsse zulässt.

Neustadt-Eberswalde, 4. Februar 1874. 